\title{
RANCANG BANGUN APLIKASI DATA MINING ANALISIS TINGKAT KELULUSAN MENGGUNAKAN ALGORITMA FP-GROWTH (Studi Kasus Di Politeknik Negeri Malang)
}

\author{
Naufal Farras Hilmy ${ }^{1}$, Banni Satria Andoko \\ Program Studi Teknik Informatika, Jurusan Teknologi Informasi, Politeknik Negeri Malang \\ JL. Soekarno-Hatta No. 9 Malang 65141, Indonesia \\ 1.naufal,farras.hilmy@gmail.com, ${ }^{2}$ ando@polinema.ac.id
}

\begin{abstract}
Abstrak
Kondisi kompetisi dan tuntutan oleh Direktorat Jenderal Pendidikan (Dikti) membuat perguruan tinggi harus memiliki keunggualan kompetitif dan kualitas agar dapat tetap bersaing dengan perguruan-perguruan tinggi lainnya. Teknologi informasi merupakan salah satu sumber daya yang dapat meningkatkan keunggulan bersaing dan dapat digunakan untuk mengolah informasi, menyebarkan informasi, serta pengambilan keputusan strategis. Tersedianya suatu informasi tidak terlepas dari melimpahnya data, dari pengolahan dan penggalian data tersebut informasi dapat diperoleh. Teknologi yang berkaitan dengan mengolah dan penggalian data menjadi informasi yang berguna adalah data mining. Teknologi data mining memiliki berbagai macam algoritma dan teknik untuk penyelesaian masalah yang berhubungan dengan data salah satunya adalah algoritma fp-growth dan teknik association rules. Dari uraian diatas dapat dibuat sebuah aplikasi untuk menganalisis tingkat kelulusan melalui teknik data mining menggunakan algoritma fp-growth. Informasi yang ditampilkan menggunakan teknik association rules yaitu menampilkan nilai support dan confidence dari masing-masing proses mining. Terbukti dari hasil pengujian yang dilakukan, algoritma fp-growth dan teknik association rules berjalan sesuai harapan dan dapat diimplemantasikan pada aplikasi data mining ini.
\end{abstract}

Kata kunci: Aplikasi, Data mining, Association rules, algoritma fp-growth, tingkat kelulusan

\section{Pendahuluan}

Perguruan tinggi saat ini dihadapkan pada kondisi kompetisi yang ketat dengan berbagai tuntutan kualitas penyelenggaraan oleh Direktorat Jenderal Pendidikan (Dikti). Kondisi ini membuat perguruan tinggi harus memiliki keunggualan kompetitif dan kualitas pelayanan pelanggan agar dapat tetap bersaing dengan perguruan-perguruan tinggi lainnya. Sistem informasi adalah merupakan salah satu sumber daya yang dapat meningkatkan keunggulan bersaing. Sistem informasi dapat digunakan untuk mendapatkan, mengolah, dan menyebarkan informasi untuk menunjang kegiatan sehari-hari serta dapat digunakan untuk pengambilan keputusan strategis.

Tersedianya suatu informasi tidak terlepas dari melimpahnya data, dari pengolahan dan penggalian data tersebut informasi dapat diperoleh. Salah satu teknologi yang berkaitan dengan mengolah data menjadi informasi yang berguna adalah data mining. Data mining sendiri merupakan istilah yang digunakan untuk menguraikan penemuan pengetahuan di dalam database. Teknologi data mining memiliki berbagai macam algoritma dan teknik untuk penyelesaian masalah yang berhubungan dengan data.

Salah satu teknik pada data mining adalah teknik asosiasi. Teknik asosiasi adalah teknik data mining untuk menemukan aturan asosiatif antara suatu kombinasi item. Teknik ini merupakan salah satu yang paling menarik dalam penggalian data. Dikatakan menarik karena teknik ini akan memberikan gambaran mengenai sejumlah sifat atau atribut tertentu yang sering muncul bersamaan dalam sebuah kumpulan data.

Frequent Pattern-Growth (FP-Growth) merupakan salah satu alternatif algoritma teknik asosiasi dalam data mining. FP-Growth dapat digunakan untuk menentukan himpunan data yang paling sering muncul dalam sebuah kumpulan data.

Dari uraian di atas, maka dapat dibuat sebuah aplikasi untuk menganalisis tingkat kelulusan melalui teknik data mining menggunakan algoritma FP-Growth. Diharapkan aplikasi ini dapat membantu dalam pengambilan keputusan oleh pihak Politeknik Negeri Malang untuk dapat mengetahui sejauh mana tingkat keberhasilan jalur masuk, tingkat keberhasilan mahasiswa dengan asal sekolah tertentu, tingkat keberhasilan jurusan atau program studi, tingkat keberhasilan berdasarkan asal kota, dan tingkat kesesuaian pekerjaan yang didapat oleh mahasiswa dengan jurusan yang diambil dengan menggunakan tolak ukur dari tingkat kelulusan.

\section{Landasan Teori}

\subsection{Data Mining}

Data mining adalah suatu istilah yang digunakan untuk menguraikan penemuan pengetahuan di dalam database. Data mining adalah 
proses yang menggunakan teknik statistic, matematika dan mengidentifikasi informasi yang bermanfaat dan pengetahuan yang terkait dari berbagai database besar (Turban, dkk. 2005).

Data mining bukanlah suatu bidang yang sama sekali baru. Salah satu kesulitan untuk mendefinisikan data mining adalah kenyataan bahwa data mining mewarisi banyak aspek teknik dari sebidang-bidang ilmu yang sudah mapan terlebih dahulu. Gambar 2.1 menunjukkan bahwa data mining memiliki akar yang panjang dari bidang ilmu seperti kecerdasan buatan (artificial Intelligent), mechine learning, statistic, database, dan juga information retrieval (Pramudiono, 2006)

\subsection{Association Rules}

Association rules (aturan asosiasi) atau analisis asosiasi dikenal juga sebagai salah satu metode data mining yang menjadi dasar dari berbagai metode data mining lainnya. Khususnya salah satu tahap dari analisis asosiasi yang disebut analisis pola frekuensi tinggi (frequent pattern mining) menarik perhatian banyak peneliti untuk menghasilkan algoritma yang efisien. Penting tidaknya suatu aturan assosiatif dapat diketahui dengan dua parameter, support (nilai penunjang) yaitu prosentase kombinasi item tersebut dalam database dan confidence (nilai kepastian) yaitu kuatnya hubungan antar item dalam aturan assosiatif. Analisis asosiasi didefinisikan suatu proses untuk menemukan semua aturan assosiatif yang memenuhi syarat minimum untuk support (minimum support) dan syarat minimum untuk confidence (minimum confidence) (Pramudiono, 2007).

Untuk mendapatkan nilai support sebuah item A dapat diperoleh dari rumus berikut:

$S=\frac{\sum(\text { Transaksi item } A)}{\sum(\text { Transaksi })}$

Sementara itu, untuk mencari nilai support dari 2-item dapat diperoleh dari rumus berikut:

$$
\begin{aligned}
& S(A, B) \\
& =\frac{\sum(\text { Transaksi item } A \text { dan } B)}{\sum(\text { Transaksi })}
\end{aligned}
$$

Sedangkan untuk mendapatkan nilai confidence dapat diperoleh dari rumus berikut

$$
\begin{aligned}
& C(A, B) \\
& =\frac{\sum(\text { Transaksi item } A \text { dan } B)}{\sum(\text { Transaksi } A)}
\end{aligned}
$$

\subsection{FP-Grwoth}

Algoritma FP-Growth adalah salah satu alternative algoritma yang dapat digunakan untuk menentukan himpunan data yang paling sering muncul. Karakteristik algoritma FP-Grwoth adalah struktur data yang digunakan adalah tree yang disebut
$F P$-Tree. Dengan menggunakan FP-Tree, algoritma $F P$-Growth dapat langsung mengekstrak frequent itemset dari FP-Tree.

Penggalian itemset yang frequent dengan menggunakan algoritma FP-Growth akan dilakukan dengan cara membangkitkan struktur data tree atau disebut dengan FP-Tree. Metode FP-Growth dapat dibagi menjadi 3 tahapan utama yaitu: (Jiawei Han, Kamber M, 2006)

1.Tahap pembangkitan conditional pattern base

2. Tahap pembangkitan conditional FP-tree

3. Tahap pencarian frequent itemset

\section{Perancangan Sistem}

\subsection{Deskripsi Sistem}

Aplikasi data mining yang dibangun adalah aplikasi berbasis desktop dengan menggunakan database lokal. Rencana pengguna dari aplikasi ini adalah bagian akademik Politeknik Negeri Malang, sehingga dari aplikasi ini diharapkan dapat memberikan informasi terkait dengan tingkat kelulusan mahasiswa diantaranya adalah dapat mengetahui sejauh mana tingkat keberhasilan proses masuk mahasiswa, tingkat keberhasilan mahasiswa dengan sekolah tertentu, tingkat keberhasilan jurusan atau program studi, dan tingkat keberhasilan berdasarkan asal kota. Tingkat keberhasilan tersebut diukur dengan IPK (Indeks Prestasi Kumulatif) yang didapat mahasiswa. Selain itu dari aplikasi ini diharapkan juga dapat memberikan informasi tentang alumni yaitu tingkat kesesuaian pekerjaan yang didapat alumni dengan jurusan yang diambil.

\subsection{Flowchart Sistem}

Berikut adalah flowchart sistem secara keseluruhan pada aplikasi data mining ini.

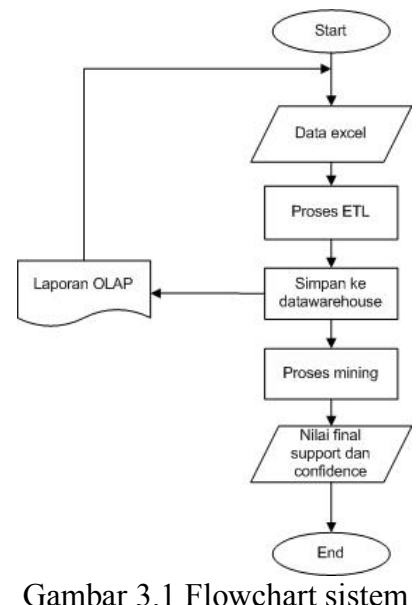

Gambar 3.1 Flowchart sistem

\subsection{Penggunaan FP-growth}

Berikut adalah salah satu contoh penggunaan algoritma fp-growth pada aplikasi data mining ini, yaitu untuk mengetahui tingkat kelulusan berdasarkan proses masuk. Diketahui threshold atau batas nilai ambang adalah $=2$. 
Tabel 3.1 Data transaksi

\begin{tabular}{|l|l|l|}
\hline \multicolumn{1}{|c|}{ NIM } & \multicolumn{1}{c|}{ IPK } & \multicolumn{1}{c|}{ PROSES MASUK } \\
\hline 1141180001 & $\mathrm{~A} 1$ & PSB/PMDK \\
\hline 1141180002 & $\mathrm{~A} 1$ & PSB/PMDK \\
\hline 1141180003 & $\mathrm{~A} 2$ & PSB/PMDK \\
\hline 1141180004 & $\mathrm{~A} 1$ & PSB/BIDIK MISI \\
\hline 1141180005 & $\mathrm{~A} 3$ & BARU UMPOL D4 \\
\hline 1141180006 & $\mathrm{~A} 2$ & BARU UMPOL D4 \\
\hline 1141180007 & $\mathrm{~A} 2$ & PSB/BIDIK MISI \\
\hline 1141180008 & $\mathrm{~A} 1$ & PSB/BIDIK MISI \\
\hline 1141180009 & $\mathrm{~A} 1$ & BARU UMPOL D3 \\
\hline 1141180010 & $\mathrm{~A} 2$ & BARU UMPOL D4 \\
\hline 1141180011 & $\mathrm{~A} 1$ & PSB/BIDIK MISI \\
\hline
\end{tabular}

Tabel 3.2 Frekuensi kemunculan item

\begin{tabular}{|l|l|}
\hline \multicolumn{1}{|c|}{ ITEM } & \multicolumn{2}{c|}{ FREKUENSI } \\
\hline A1 & 6 \\
\hline A2 & 4 \\
\hline PSB/BIDIK MISI & 4 \\
\hline PSB/PMDK & 3 \\
\hline BARU UMPOLD4 & 3 \\
\hline
\end{tabular}

Tabel 3.3 Data transaksi terorder

\begin{tabular}{|c|c|}
\hline TID & ITEMSET \\
\hline 1141180001 & $\{\mathrm{~A} 1 ; \mathrm{PSB} / \mathrm{PMDK}\}$ \\
\hline 1141180002 & $\{\mathrm{~A} 1 ; \mathrm{PSB} / \mathrm{PMDK}\}$ \\
\hline 1141180003 & $\{\mathrm{~A} 2 ; \mathrm{PSB} / \mathrm{PMDK}\}$ \\
\hline 1141180004 & $\{\mathrm{~A} 1 ; \mathrm{PSB} / \mathrm{BIDIK} / \mathrm{MISI}\}$ \\
\hline 1141180005 & $\{$ BARU UMPOL D4\} \\
\hline 1141180006 & $\{\mathrm{~A} 2 ;$ BARU UMPOL D 4$\}$ \\
\hline 1141180007 & $\{\mathrm{~A} 2 ; \mathrm{PSB} / \mathrm{BIDIK}$ MISI $\}$ \\
\hline 1141180008 & $\{\mathrm{~A} 1 ; \mathrm{PSB} / \mathrm{BIDIK}$ MISI $\}$ \\
\hline 1141180009 & $\{\mathrm{~A} 1\}$ \\
\hline 1141180010 & $\{\mathrm{~A} 2 ;$ BARU UMPOL D 4$\}$ \\
\hline 1141180011 & $\{\mathrm{~A} 1 ; \mathrm{PSB} / \mathrm{BIDIK}$ MISI $\}$ \\
\hline
\end{tabular}

Setelah didapatkan data transaksi yang sesuai dengan nilai batas ambang atau nilai threshold, selanjutnya adalah proses $f p$-tree.

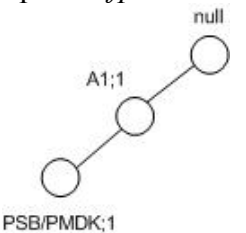

Gambar 3.2 tree setelah tid 1

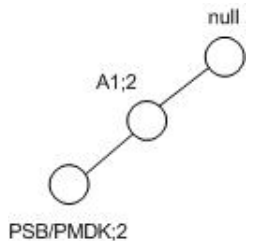

Gambar 3.3 tree setelah tid 2

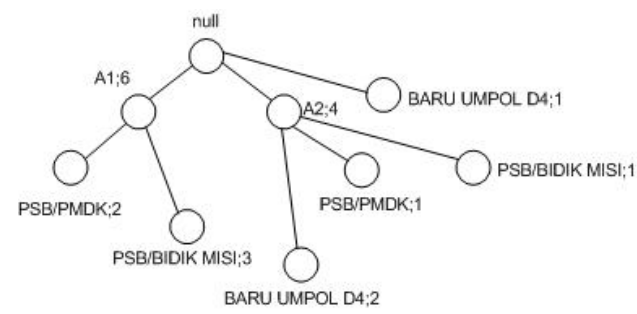

Gambar 3.4 tree setelah tid ke 11

Selanjutnya langkah algoritma fp-growth. Berikut adalah tahap conditional pattern base.

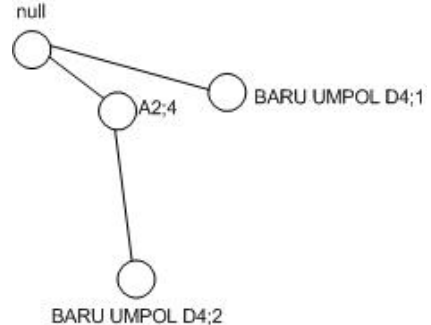

Gambar 3.5 lintasan mengandung baru umpol D4

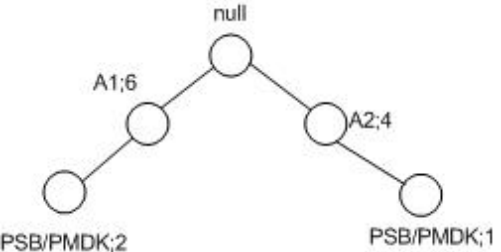

Gambar 3.6 lintasan mengandung psb/pmdk

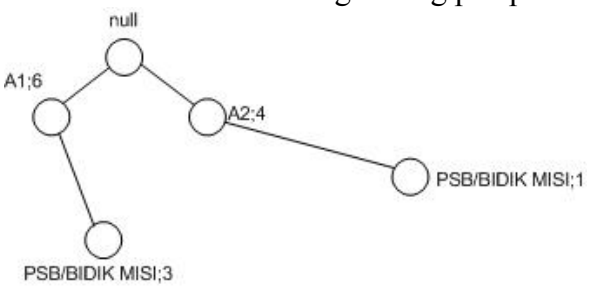

Gambar 3.7 lintasan mengandung psb/bidik misi<smiles>Oc1ccccc1</smiles>

Gambar 3.8 lintasan mengandung A2

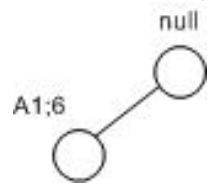

Gambar 3.9 lintasan mengandung A1

Setelah tahap conditional pattern base, selanjutnya adalah tahap conditional fp-tree. Pada tahap ini nilai item pada tree yang kurang dari batas nilai ambang atau nilai threshold akan dihapus. Berikut salah satu contoh conditional fp-tree pada item baru umpol D4.

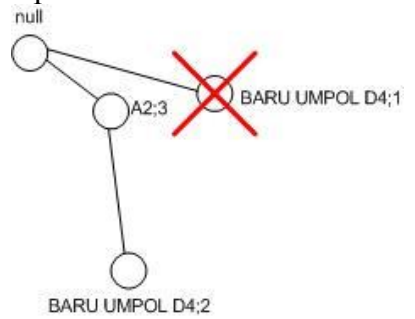

Gambar 3.10 Conditional fp-tree baru umpol D4

Didapat frequent item set pada item baru umpol D4 adalah $\{$ A2; Baru Umpol d4 $\}$. Berikut hasil frequent item set secara keseluruhan. 
Tabel 3.4 Frequent itemset

\begin{tabular}{|l|l|}
\hline \multicolumn{1}{|c|}{ SUFFIX } & \multicolumn{1}{c|}{ FREQUENT ITEMSET } \\
\hline BARU UMPOLD4 & $\{$ A2;BARUUMPOLD $\}$ \\
\hline PSB/PMDK & $\{$ A; PSB/PMDK $\}$ \\
\hline PSB/BIDIK MISI & $\{$ A1;PSB/BIDIK MISI $\}$ \\
\hline A2 & $\{\mathrm{A} 2\}$ \\
\hline A1 & $\{\mathrm{A} 1\}$ \\
\hline
\end{tabular}

Setelah didapat frequent itemset atau kombinasi item yang paling sering muncul. Selanjutnya adalah menghitung nilai support dan confidence.

Tabel 3.5 Hasil perhitungan

\begin{tabular}{|l|l|c|}
\hline \multirow{2}{*}{ Frequent Item } & \multicolumn{1}{c|}{$\begin{array}{c}\text { Nilai } \\
\text { Perhitungan }\end{array}$} & Hasil \\
\hline \multirow{3}{*}{$\mathrm{A} 1 ; \mathrm{PSB} / \mathrm{BIDIK}$ MISI } & Support & $27.27 \%$ \\
\cline { 2 - 3 } & Confidence & $50.00 \%$ \\
\cline { 2 - 3 } & Final & $13.64 \%$ \\
\hline \multirow{3}{*}{$\mathrm{A} 1 ; \mathrm{PSB} / \mathrm{PMDK}$} & Support & $18.18 \%$ \\
\cline { 2 - 3 } & Confidence & $33.33 \%$ \\
\cline { 2 - 3 } & Final & $6.06 \%$ \\
\hline \multirow{2}{*}{$\mathrm{A} 2 ; \mathrm{BARU}$} & $18.18 \%$ \\
\hline & Support & $50.00 \%$ \\
\cline { 2 - 3 } & Confidence & $9.09 \%$ \\
\cline { 2 - 3 } & Final & \\
\hline
\end{tabular}

\subsection{Perancangan Struktur table}

Proses mining pada aplikasi ini adalah menggunakan store procedure pada sql server sedangkan implementasi dari algoritma fp-growth adalah menggunakan struktur temporary tabel. Alasan dari menggunakan temporary tabel adalah karena proses-proses mining tidak perlu disimpan permanen didalam database sehingga membuat database menjadi berat, jadi setiap eksekusi mining akan membuat temporary tabel. Berikut adalah struktur temporary tabel pada algoritma fp-growth.

\begin{tabular}{|l|l|c|}
\hline \multicolumn{1}{|c|}{ Nama Field } & \multicolumn{1}{c|}{ Tipe data } & \multicolumn{1}{c|}{ Keterangan } \\
\hline tid & int & \\
\hline item & varchar(1000) & \\
\hline
\end{tabular}

Gambar 3.10 Struktur tabel tabel_trans_fp

\begin{tabular}{|l|l|l|}
\hline \multicolumn{1}{|c|}{ Nama Field } & \multicolumn{1}{c|}{ Tipe data } & \multicolumn{1}{c|}{ Keterangan } \\
\hline item & varchar(100) & \\
\hline support & int & \\
\hline
\end{tabular}

Gambar 3.11 Struktur tabel tabel_total_count

\begin{tabular}{|l|l|l|}
\hline \multicolumn{1}{|c|}{ Nama Field } & \multicolumn{1}{c|}{ Tipe data } & \multicolumn{1}{c|}{ Keterangan } \\
\hline tid & int & \\
\hline item & varchar $(100)$ & \\
\hline
\end{tabular}

Gambar 3.12 Struktur tabel tabel_sorted_trans

\begin{tabular}{|l|l|l|}
\hline \multicolumn{1}{|c|}{ Nama Field } & \multicolumn{1}{c|}{ Tipe data } & \multicolumn{1}{c|}{ Keterangan } \\
\hline item & varchar(100) & \\
\hline cnt & int & \\
\hline path & varchar(1000) & \\
\hline
\end{tabular}

Gambar 3.13 Struktur tabel tabel_before_tree

\begin{tabular}{|l|l|l|}
\hline \multicolumn{1}{|c|}{ Nama Field } & \multicolumn{1}{c|}{ Tipe data } & \multicolumn{1}{c|}{ Keterangan } \\
\hline item & varchar(100) & \\
\hline cnt & int & \\
\hline path & varchar(1000) & \\
\hline
\end{tabular}

Gambar 3.14 Struktur tabel tabel_fp_tree

\begin{tabular}{|l|l|l|}
\hline \multicolumn{1}{|c|}{ Nama Field } & \multicolumn{1}{c|}{ Tipe data } & \multicolumn{1}{c|}{ Keterangan } \\
\hline tid & varchar(50) & \\
\hline id & int & \\
\hline item & varchar(100) & \\
\hline cnt & int & \\
\hline
\end{tabular}

Gambar 3.15 Struktur tabel tabel_pattern_base

\begin{tabular}{|l|l|c|}
\hline \multicolumn{1}{|c|}{ Nama Field } & \multicolumn{1}{c|}{ Tipe data } & \multicolumn{1}{c|}{ Keterangan } \\
\hline prefix & varchar(50) & \\
\hline item & varchar(100) & \\
\hline cnt & int & \\
\hline
\end{tabular}

Gambar 3.16 Struktur tabel tabel_cond_pattern

\begin{tabular}{|l|l|l|}
\hline \multicolumn{1}{|c|}{ Nama Field } & \multicolumn{1}{c|}{ Tipe data } & \multicolumn{1}{c|}{ Keterangan } \\
\hline item & varchar(50) & \\
\hline fp & varchar(1000) & \\
\hline cnt & Int & \\
\hline
\end{tabular}

Gambar 3.17 Struktur tabel tabel_freq pattern

\begin{tabular}{|l|l|l|}
\hline \multicolumn{1}{|c|}{ Nama Field } & \multicolumn{1}{c|}{ Tipe data } & \multicolumn{1}{c|}{ Keterangan } \\
\hline item & varchar(50) & \\
\hline fp & $\operatorname{varchar}(1000)$ & \\
\hline cnt & Int & \\
\hline
\end{tabular}

Gambar 3.18 Struktur tabel tabel_temp_fp

\section{Implementasi}

\subsection{Implementasi Program}

Implementasi program adalah tampilan hasil dari perancangan dan analisis sistem yang telah dibuat, berikut adalah tampilan hasil dari perancangan dan analisis sistem program.

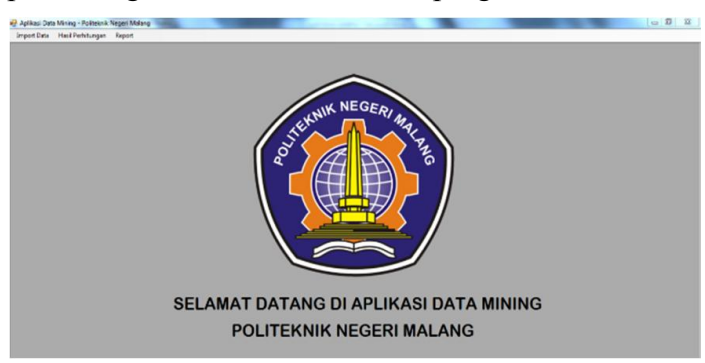

Gambar 4.1 Borang utama

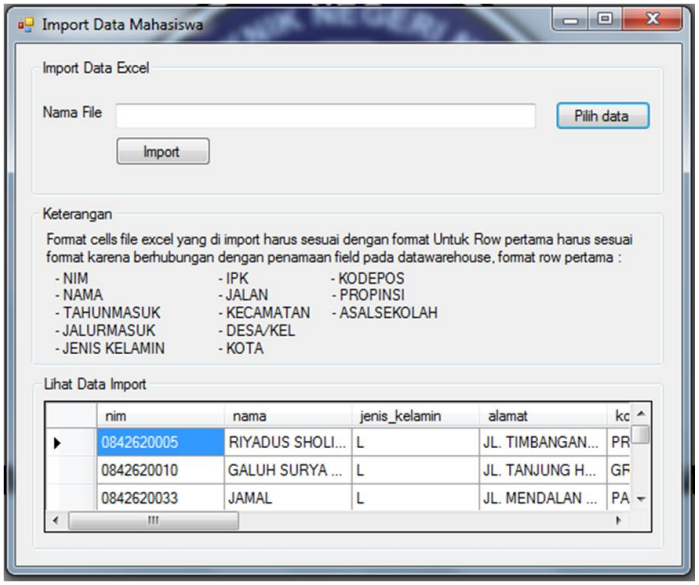

Gambar 4.2 Borang import data 


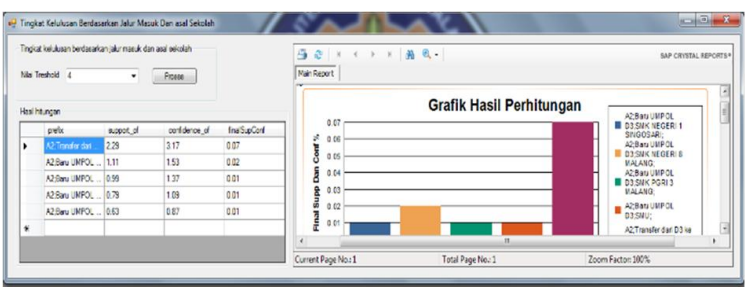

Gambar 4.3Salah satu borang perhitungan

\section{Pengujian dan Pembahasan}

Pengujian pada sistem ini meliputi beberapa jenis pengujian, yaitu pengujian fungsional, pengujian metode.

\subsection{Pengujian Fungsional}

Pengujian fungsional dilakukan untuk mengetahui apakah fitur-fitur dari aplikasi mining ini berjalan dengan semestinya atau tidak. Teknik yang digunakan dalam pengujian fungsional ini adalah teknik blackbox.

Berdasarkan hasil pengujian fungsional dapat ditarik kesimpulan bahwa aplikasi mining ini telah berjalan sesuai dengan harapan dan dapat menampilkan hasil perhitungan dari masing-masing proses mining.

\subsection{Pengujian Metode}

Selain melakukan pengujian fungsional pada aplikasi dilakukan juga pengujian metode dan algoritma pada aplikasi, yaitu metode association rule dan algoritma $f p$-growth. Pengujian dilakukan dengan cara percobaan secara manual dan percobaan terkomputerisasi pada aplikasi. Jika hasil perhitungan sesuai atau sama, baik secara manual dan terkomputerisasi maka dapat disimpulkan bahwa metode dan algoritma pada aplikasi mining ini berjalan sesuai dengan harapan. Berikut tabel hasil pengujian metode.

Tabel 5.1 hasil pengujian metode

\begin{tabular}{|l|l|c|c|}
\hline \multirow{2}{*}{ Frequent Item } & $\begin{array}{c}\text { Nilai } \\
\text { Perhitungan }\end{array}$ & $\begin{array}{c}\text { Percobaan } \\
\text { Manual }\end{array}$ & $\begin{array}{c}\text { Percobaan } \\
\text { Aplikasi }\end{array}$ \\
\hline \multirow{3}{*}{ A1;PSB $/$ BIDIK MISI } & Support & $27.27 \%$ & $27.27 \%$ \\
\cline { 2 - 4 } & Confidence & $50.00 \%$ & $50.00 \%$ \\
\cline { 2 - 4 } & Final & $13.64 \%$ & $13.64 \%$ \\
\hline \multirow{3}{*}{ A1;PSB $/$ PMDK } & Support & $18.18 \%$ & $18.18 \%$ \\
\cline { 2 - 4 } & Confidence & $33.33 \%$ & $33.33 \%$ \\
\cline { 2 - 4 } & Final & $6.06 \%$ & $6.06 \%$ \\
\hline \multirow{3}{*}{ A2;BARUUMPOLD4 } & Support & $18.18 \%$ & $18.18 \%$ \\
\cline { 2 - 4 } & Confidence & $50.00 \%$ & $50.00 \%$ \\
\cline { 2 - 4 } & Final & $9.09 \%$ & $9.09 \%$ \\
\hline
\end{tabular}

Berdasarkan tabel hasil percobaan diatas dapat ditarik kesimpulan bahwa metode association rule dan algoritma fp-growth berjalan sesuai harapan dan berhasil diimplemantasikan pada aplikasi data mining ini, karena perhitungan yang dihasilkan dari percobaan manual dan percobaan aplikasi cocok $100 \%$.

\section{Kesimpulan dan Saran}

\subsection{Kesimpulan}

Setelah melakukan analisis, perancangan, implementasi beserta pengujian yang dilakukan, maka dapat ditarik beberapa kesimpulan, yaitu :

1. Algoritma fp-growth dapat diimplementasikan pada aplikasi mining ini, dari hasil analisis, perancangan, implementasi dan pengujian terbukti algoritma fp-growth dapat menampilkan informasi tingkat kelulusan berdasarkan asal sekolah, program studi, asal kota, proses masuk, serta dapat menampilkan informasi tingkat kesesuaian pekerjaan yang didapat alumni berdasarkan program studi.

2. Hasil dari aplikasi mining ini dapat digunakan sebagai pertimbangan dalam pengambilan sebuah keputusan berdasar pada tingkat kelulusan. Contoh keputusan penambahan kuota pada jalur masuk tertentu dilihat dari tingkat kelulusan.

\subsection{Saran}

Berdasarkan penelitian yang dilakukan, berikut saran untuk pengembangan aplikasi data mining ini lebih lanjut, yaitu aplikasi diubah menjadi web based application, karena penyajian laporan OLAP lebih dinamis dan lebih menarik dibandingkan desktop aplication.

\section{Daftar Pustaka:}

Alves, Ronnie. 2007. Programming Relational Databases For Itemset Mining Over Large Transaction Tables. Portugal : University of Minho.

Erwin. 2009. Analisis Market Basket Dengan Algoritma Apriori dan FP-Growth. Palembang: Universitas Sriwijaya.

Fathimah Fatihatul, Atje Setiawan, Rudi Rosadi. 2011. Asosiasi Data Mining Menggunakan Algoritma FP-Growth Untuk Market Basket Analysis. Jatinagor: Universitas Padjadjaran.

Hermawati, Fajar Astuti. 2013. Data Mining. Yogyakarta: Penerbit Andi.

Huda, Nuqson Masykur. 2010 Aplikasi Data Mining Untuk Menampilkan Informasi Tingkat Kelulusan Mahasiswa (Studi Kasus di Fakultas MIPA Universitas Diponegoro) Semarang : Universitas Diponegoro

Kusrini, dan Emha Taufiq L. 2009. Algoritma Data Mining. Yogyakarta: Penerbit Andi.

Ririanti. 2014. Implementasi Algoritma FP-Growth Pada Aplikasi Prediksi Persediaan Sepeda Motor (Studi Kasus PT.Pilar Deli Labumas). Medan: STMIK Budi Darma Medan.

Samuel, David. 2007. Penerapan Struktur FP-Tree dan Algoritma FP-Growth dalam Optomasi Penentuan Frequent Itemset. Bandung : Institut Teknologi Bandung.

Susanto, Sani, dan Dedy Suryadi. 2010. Pengantar Data Mining. Yogyakarta: Penerbit Andi. 